\title{
Faktor-Faktor yang Memengaruhi Pengungkapan Emisi Karbon pada Perusahaan yang Terdaftar di Bursa Efek Indonesia
}

\author{
Ni Nengah Witri Astiti ${ }^{1}$ \\ Fakultas Ekonomi dan Bisnis \\ Universitas Udayana, Indonesia \\ Email : witriastiti30@gmail.com
}

\author{
Dewa Gede Wirama² \\ Fakultas Ekonomi dan Bisnis \\ Universitas Udayana, Indonesia
}

\begin{abstract}
ABSTRAK
Pemanasan global merupakan salah satu masalah lingkungan yang menyebabkan perubahan iklim terutama terkait dengan emisi karbon perusahaan. Penelitian ini bertujuan untuk menguji faktor-faktor yang memengaruhi pengungkapan emisi karbon. Penelitianini dilakukan pada seluruh perusahaan yang terdaftar di Bursa Efek Indonesia yang mengungkapkan informasi terkait emisi karbon pada laporan tahunan tahun 2018. Sampel dala m penelitian ini dipilih secara purposif, menghasilkan sampel dengan 37 perusahaan. Teknik analisis data dalam penelitian ini adalah regresi linear berganda. Hasil analisis menunjukkan tipe industri dan good corporate governance berpengaruh positif, sedangkan leverage berpengaruh negatif pada pengungkapan emisi karbon. Ukuran perusahaan dan profitabilitas tidak memengaruhi pengungkapan emisi karbon.
\end{abstract}

Kata Kunci: Pemanasan Global; Perubahan Iklim; Pengungkapan Emisi Karbon.

\section{Factors That Influence Carbon Emission Disclosures in Companies Listed on the Indonesia Stock Exchange}

\section{ABSTRACT}

Global warming is one of the environmental problems that causes climate change, especially related to corporate carbon emissions. This study aims to examine the factors that influence the disclosure of carbon emissions. This research was conducted on all companies listed on the Indonesia Stock Exchange that revealed information related to carbon emissions in the annual report in 2018. The sample in this research was selected purposively, producing samples with 37 companies. The data analysis technique in this research is multiple linear regression. The analysis shows that company the type of industry and good corporate governance has a positive effect, while leverage has a negative effect on disclosure of carbon emissions. Company size and profitability do no affect carbon emissions disclosure.

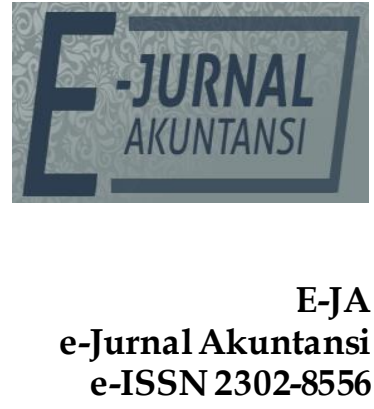

\author{
Vol. 30 No. 7 \\ Denpasar, Juli 2020 \\ Hal.1796-1810 \\ Artikel Masuk: \\ 12 Maret 2020
}

Tanggal Diterima: 16 Juni 2020

Keywords: $\quad$ Global Warming; Climate Change; Carbon Emission Disclosures.

The Article is Available in: https://ojs.unud.ac.id/index.php/Akuntansi/index 


\section{PENDAHULUAN}

Di Indonesia, pengungkapan emisi karbon oleh perusahaan belum banyak diterapkan oleh perusahaan karena pengungkapan tersebut masih bersifat sukarela (voluntary disclosure). Pengungkapan laporan terkait aktivitas lingkungan yang dilakukan oleh perusahaan merupakan jenis informasi nonkeuangan (Dewi \& Yasa, 2017). Pengungkapan (disclosure) berarti tidak menutupi atau tidak menyembunyikan, dan pengungkapan ini merupakan salah satu laporan sebagai salah satu indikator keberhasilan perusahaan dan stakeholder menganggap ini merupakan salah satu langkah yang positif yang dapat menjaga nama baik perusahaan (Urmila \& Mertha, 2017).

Suatu perusahaan jika kurang peduli terhadap lingkungannya maka akan mendapatkan kerugian, baik yang terjadi secara langsung saat itu maupun yang terjadi di masa yang akan datang (Putri \& Wirajaya, 2019). Menurut Wulandari \& Wirajaya (2014) informasi-informasi yang diungkapkan perusahaan pada laporan tahunannya diharapkan dapat mengurangi ketidakpastian prospek perusahaan di masa mendatang. Dengan adanya pengungkapan informasi terkait aktivitas perusahaan pada laporan tahunan perusahaan, hal itu dapat digunakan sebagai pengalihan perhatian masyarakat dari dampak buruk yang ditimbulkan perusahaan dari aktivitas operasinya (Astuti \& Wirama, 2016).

Menurut Ghomi \& Leung (2013) isu yang berkaitan dengan perubahan iklim serta diakibatkan oleh adanya pemanasan global menyebabkan adanya kebijakan baru terkait lingkungan dalam beberapa tahun terakhir. Menanggapi isu tersebut perusahaan diharapkan dapat memberi perhatian yang lebih serius terhadap pengungkapan emisi karbon perusahaan. Hal tersebut terlihat dari bertambahnya negara anggota Persatuan Bangsa-Bangsa yang meratifikasi Protokol Kyoto. Indonesia meratifikasi Protokol Kyoto periode pertama pada tanggal 28 Juni 2004. Indonesia sepakat ikut serta menurunkan emisi gas rumah kaca yang berdampak pada perubahan iklim secara global dengan pengesahan Undang-Undang No. 17 Tahun 2004. Indonesia meratifikasi kembali Protokol Kyoto pada tanggal 30 September 2014.

Teori legitimasi merupakan teori yang mendasari perusahaan dalam mengungkapkan laporan pertanggungjawaban sosial dan lingkungan seperti salah satunya pengungkapan emisi karbon. Dowling \& Pfeffer (1975) mengatakan bahwa organisasi berusaha menciptakan kesesuaian antara nilainilai sosial yang ada pada kegiatannya dengan norma-norma yang pada sistem sosial masyarakat di mana organisasi merupakan bagian dari sistem sosial masyarakat. Legitimasi yang ingin didapatkan oleh perusahaan dari masyarakat adalah bahwa aktivitas operasi perusahaan telah sesuai dengan norma dan ketentuan yang berlaku (Deegan \& Unerman, 2011).

Sejalan dengan teori legitimasi, teori stakeholder menyatakan bahwa perusahaan bukanlah entitas yang hanya beroperasi untuk kepentingan perusahaan sendiri, melainkan juga dapat memberikan manfaat bagi seluruh stakeholder. Menurut Peng et al. (2015), salah satu faktor utama yang menyebabkan perusahaan peduli pada lingkungan dan melakukan pengungkapan emisi karbon karena ada tekanan dari regulator (pemerintah). Keberlangsungan suatu perusahaan dalam menjalankan operasional perusahaannya sangat dipengaruhi oleh dukungan yang diberikan oleh 
stakeholder kepada perusahaan tersebut (Pratiwi \& Sari, 2016). Teori stakeholder menjelaskan bahwa perusahaan harus selalu menjaga hubungan dengan para stakeholder dengan memenuhi kebutuhan mereka. Stakeholder memiliki kuasa atas ketersediaan sumber daya, baik sumber daya alam maupun sumber daya manusia yang akan digunakan untuk operasional perusahaan, seperti tenaga kerja, pasar atas produk perusahaan dan sebagainya.

Menurut Pratiwi (2018), perusahaan wajib untuk peduli dengan perubahan iklim yang terjadi saat ini karena juga merupakan akibat aktivitas perusahaan dalam melakukan kegiatan produksi. Pengungkapan lingkungan oleh perusahaan mencakup intensitas emisi gas rumah kaca, kinerja terhadap target pengurangan emisi karbon, penggunaan energi dan strategi untuk menjaga lingkungan dari dampak perubahan iklim akibat pemanasan global serta dampak dan peluang dari perubahan iklim (Cotter \& Najah, 2012). Menurut Andrew \& Cortese (2011), pengungkapan emisi karbon digunakan untuk pengambilan keputusan internal maupun eksternal. Namun, perbedaan kepentingan masing-masing perusahaan menyebabkan perbedaan pula dalam pengungkapan tanggung jawabnya kepada lingkungan.

Pengungkapan terkait aktivitas lingkungan oleh perusahaan dipengaruhi oleh beberapa faktor. Faktor-faktor tersebut meliputi umur perusahaan, tipe industri, ukuran perusahaan, kinerja lingkungan, leverage, good corporate governance, profitabilitas, struktur kepemilikan, dan budaya bisnis (Dewi \& Yasa, 2017). Terdapat berbagai penelitian terdahulu yang meneliti tentang faktor-faktor yang memengaruhi pengungkapan emisi karbon.

Teori legitimasi menjelaskan bahwa perusahaan besar mendapatkan tekanan lebih besar dari masyarakat terkait dengan permasalah lingkungan tempat perusahaan beroperasi, maka dari itu perusahaan harus meningkatkan kepeduliannya pada lingkungan. Hal tersebut akan memotivasi suatu perusahaan besar untuk mengungkapkan secara lebih luas informasi dari kegiatan perusahaan dalam pelestarian lingkungan. Dengan pengungkapan emisi karbon bisa menjadi salah satu cara perusahaan untuk membangun citra baik perusahaan di masyarakat. Berdasarkan uraian tersebut maka hipotesis pertama dalam penelitian ini adalah:

$\mathrm{H}_{1}$ : Ukuran perusahaan berpengaruh positif pada pengungkapan emisi karbon.

Jannah \& Muid (2014), Stanny \& Ely (2008) dan Lorenzo et al. (2009) menyatakan ukuran perusahaan memiliki pengaruh yang signifikan pada pengungkapan emisi karbon, sedangkan Irwhantoko \& Basuki (2016), Linggasari (2015), serta Pratiwi (2018) menunjukkan bahwa ukuran perusahaan tidak memiliki pengaruh pada pengungkapan emisi karbon. Hipotesis pertama penelitian ini merupakan pengujian kembali atas penelitian tersebut.

Berdasarkan teori legitimasi, perusahaan yang memiliki kinerja keuangan yang baik akan mendapatkan tekanan dari masyarakat untuk mengungkapkan informasi terkait lingkungan pada laporan tahunan. Hal tersebut sejalan dengan penelitian Pradini (2013) menyatakan perusahaan yang memiliki kinerja keuangan baik akan semakin besar kemungkinan perusahaan memperluas pengungkapan terkait emisi dari aktivitas operasional perusahaan. Profitabilitas suatu perusahaan adalah hal yang sering menjadi perhatian karena profitabilitas menunjukkan keberhasilan perusahaan. Perusahaan yang memiliki profitabilitas 
yang tinggi akan mendapat tekanan tinggi dari stakeholders, dan oleh karena itu perusahaan perlu melakukan pengungkapan lingkungan yang lebih luas, termasuk pengungkapan emisi karbon. Berdasarkan uraian tersebut maka hipotesis kedua dalam penelitian ini adalah:

$\mathrm{H}_{2}$ : Profitabilitas berpengaruh positif pada pengungkapan emisi karbon.

Jannah \& Muid (2014) menemukan hubungan positif antara profitabilitas dan pengungkapan emisi karbon. Hasil tersebut tidak konsisten dengan penelitian Pratiwi (2018), Irwhantoko \& Basuki (2016), serta Pratiwi \& Sari (2016) yang menjelaskan bahwa profitabilitas tidak memiliki pengaruh pada pengungkapan emisi karbon. Sebagaimana halnya dengan hipotesis pertama, hipotesis kedua penelitian ini juga merupakan pengujian kembali atas penelitian sebelumnya.

Perusahaan dengan tingkat leverage tinggi akan lebih berhati-hati dalam melakukan pengungkapan pada laporan tahunan terutama terkait pengeluaranpengeluaran yang berkaitan dengan tindakan pencegahan emisi karbon (Luo et al., 2013). Perusahaan yang memiliki tingkat leverage tinggi akan terbebani jika harus menyediakan informasi tambahan. Semakin tinggi tingkat leverage suatu perusahaan maka pengungkapan lingkungan yang dilakukan oleh perusahaan tersebut akan semakin rendah dan begitu pula sebaliknya. Beban utang dan bunga yang tinggi merupakan salah satu alasan perusahaan mengurangi biayabiaya untuk mencegah emisi karbon dari aktivitas produksinya dan melakukan pengungkapan emisi karbon perusahaan (Jannah \& Muid, 2014). Berdasarkan uraian tersebut maka hipotesis ketiga dalam penelitian ini adalah:

$\mathrm{H}_{3}$ : Leverage berpengaruh negatif pada pengungkapan emisi karbon.

Irwhantoko \& Basuki (2016) dan Clarkson et al. (2008) menyatakan bahwa leverage berpengaruh negatif pada pengungkapan emisi karbon. Penelitian tersebut menunjukkan hasil yang berbeda dengan D'Amico et al. (2016) dan Eleftheriadis \& Anagnostopoulou (2015) yang menyatakan leverage tidak berpengaruh pada pengungkapan emisi karbon. Hipotesis ketiga penelitian ini menguji kembali penelitian-penelitian tersebut.

Perusahaan high profile seperti perusahaan manufaktur dan pertambangan akan cenderung lebih luas dalam mengungkapkan tanggung jawab mereka terhadap lingkungan dibandingkan dengan tipe industri yang tergolong low profile seperti perusahaan lainnya di bidang keuangan, jasa, dan lain sebagainya (Jannah \& Muid, 2014). Menurut Wang et al. (2013) aktivitas operasional perusahaan yang tergolong tipe industri high profile memiliki dampak yang tinggi terhadap lingkungan sehingga ada tekanan untuk melakukan kegiatan terkait dengan tanggung jawabnya terhadap lingkungan. Berdasarkan uraian tersebut maka hipotesis keempat dalam penelitian ini adalah:

$\mathrm{H}_{4}$ : Tipe industri berpengaruh positif pada pengungkapan emisi karbon.

Pengungkapan emisi karbon merupakan salah satu bagian dari corporate social responsibility yang memiliki kaitan erat dengan good corporate governance. Tanggung jawab sosial dan lingkungan berorientasi kepada stakeholder, yang sejalan dengan prinsip utama good corporate governance yaitu prinsip responsibility. Pengungkapan pelaksanaan tanggung jawab sosial maupun lingkungan perusahaan sejalan dengan prinsip good corporate governance yaitu 
prinsip transparansi. Penelitian terkait kualitas corporate governance dilakukan oleh Choi et al. (2013) yang menemukan pengaruh kualitas corporate governance dengan pengungkapan emisi karbon. Adanya pengungkapan terkait emisi karbon dalam laporan perusahaan dinilai menunjukkan transparansi dalam memberikan informasi kepada publik. Berdasarkan uraian tersebut maka hipotesis kelima dalam penelitian ini adalah:

$\mathrm{H}_{5}$ : Good corporate governance berpengaruh positif pada pengungkapan emisi karbon.

\section{METODE PENELITIAN}

Pendekatan yang digunakan pada penelitian ini adalah pendekatan kuantitatif yang berbentuk asosiatif. Objek penelitian adalah pengungkapan emisi karbon. Data diperoleh dari laman Bursa Efek Indonesia (www.idx.co.id) tahun 2018.

Variabel dependen, yaitu pengungkapan emisi karbon, diukur dengan rasio total item yang diungkapkan dibandingkan dengan 18 item pengungkapan berdasarkan checklist dari penelitian Choi et al. (2013). Pengungkapan tersebut terdiri atas beberapa kategori, yaitu perubahan iklim (climate change), emisi gas rumah kaca (greenhouse gas), konsumsi energi (energy consumption), biaya dan pengurangan gas rumah kaca (reduction and cost) serta akuntabilitas emisi karbon (accountability of carbon emission). Setiap item pengungkapan diberi skor dan skor total kemudian dibagi 18 sesuai dengan total item seperti disajikan pada Persamaan 1. Variabel ini diberi notasi CED (singkatan dari carbon emission disclosure).

$C E D=\frac{\text { total item diungkapkan }}{18}$

Variabel independen yang digunakan pada penelitian ini yakni ukuran perusahaan, profitabilitas, leverage, tipe industri dan good corporate governance. Ukuran perusahaan (UP) menggunakan proksi log natural total aset (Jannah \& Muid, 2014). Perhitungan ukuran perusahaan adalah sebagai berikut.

$U P=\ln ($ total aset $)$...

Profitabilitas (PROF) merupakan kemampuan perusahaan dalam menghasilkan laba. Profitabilitas (PROF) dalam penelitian ini diukur dengan menggunakan perbandingan antara laba bersih dengan total aset (Jannah \& Muid, 2014). Rumus perhitungan rasio PROF adalah sebagai berikut.

PROF $=\frac{\text { lababersih }}{\text { total aset }}$

Leverage (LEV) merupakan rasio yang mengukur sejauh mana perusahaan menggunakan pendanaan melalui utang. Leverage dalam penelitian ini diukur dengan debt to equity ratio, yaitu perbandingan total utang dengan total ekuitas (Jannah \& Muid, 2014). Rumus perhitungan rasio LEV adalah sebagai berikut. $L E V=\frac{\text { totalutang }}{\text { total ekwitas }}$.

Tipe industri (TI) dalam penelitian ini diukur menggunakan variabel dummy yaitu memberi skor 1 untuk perusahaan yang tergolong dalam kategori industri high profile dan skor 0 pada perusahaan tergolong dalam kategori industri low profile (Choi et al., 2013).

Good corporate governance (GCG) diukur dengan menghitung skor dari masing-masing instrumen GCG dan menjumlahkan skor tersebut untuk 
mendapatkan satu nilai GCG. Dalam penelitian ini GCG diukur dengan instrumen pengukuran berdasarkan mekanisme GCG mengikuti Wahidahwati (2012).

Kriteria pemberian skor dari instrumen GCG yaitu dewan komisaris dan kepemilikan institusional disajikan pada Tabel 1, sebagai berikut.

Tabel 1. Dewan Komisaris Dan Kepemilikan Institusinal

\begin{tabular}{|c|c|c|c|c|c|c|c|c|c|}
\hline \multicolumn{8}{|c|}{ Dewan Komisaris (DK) : 45\% } & \multicolumn{2}{|c|}{$\begin{array}{c}\text { Kepemilikan } \\
\text { Institusional : } 15 \%\end{array}$} \\
\hline \multicolumn{2}{|c|}{$\begin{array}{l}\text { Ukuran } \\
\text { DK }\end{array}$} & \multicolumn{2}{|c|}{$\begin{array}{l}\text { Proporsi DK } \\
\text { Independen }\end{array}$} & \multicolumn{2}{|c|}{$\begin{array}{c}\text { Kepemilikan } \\
\text { DK }\end{array}$} & \multicolumn{2}{|c|}{$\begin{array}{c}\text { KAP } \\
\text { (big four) }\end{array}$} & $\begin{array}{l}\text { Kepemili } \\
\text { Institusic }\end{array}$ & \\
\hline Range & Score & Range & Score & Range & Score & & Score & Range & Score \\
\hline $0-3$ & 2 & $0 \%-20 \%$ & 2 & $0 \%-20 \%$ & 2 & $\overline{Y a}$ & 5 & $0 \%-20 \%$ & 2 \\
\hline $4-6$ & 4 & 2 & 4 & 21 & 4 & Tidak & 0 & 21 & 4 \\
\hline $6-8$ & 6 & & 6 & & 6 & & & 41 & 6 \\
\hline $9-11$ & 0 & $61 \%-$ & 8 & $61 \%-80 \%$ & 8 & & & $61 \%-80 \%$ & 8 \\
\hline$>11$ & 10 & $>80 \%$ & 10 & $>80 \%$ & 10 & & & $>80 \%$ & 10 \\
\hline
\end{tabular}

Sumber:Wahidahwati, 2012

Pada Tabel 1, menunjukkan skor minimal yang diberikan adalah 2 dan skor maksimal adalah 10. Jika perusahaan yang menggunakan KAP big four diberikan skor 5 dan skor 0 jika perusahaan tidak menggunakan KAP big four. Dewan komisaris dihitung dengan menjumlahkan skor dari ukuran dewan komisaris, proporsi dewan komisaris independen, kepemilikan dewan komisaris dan KAP, kemudian mengalikan jumlah skor tersebut dengan $20 \%$. Kepemilikan institusional dihitung dengan mencari skor dari kepemilikan institusional kemudian dikalikan $15 \%$.

Kriteria pemberian skor dari instrumen GCG yaitu komite audit disajikan pada Tabel 2, sebagai berikut.

Tabel 2. Komite Audit

\begin{tabular}{cccccc}
\hline \multicolumn{5}{c}{ Komite Audit : 20\% } \\
\hline Ukuran Komite Audit & \multicolumn{2}{c}{$\begin{array}{c}\text { Proporsi Komite Audit } \\
\text { Independen }\end{array}$} & \multicolumn{2}{c}{$\begin{array}{c}\text { Keahlian } \\
\text { (fine expert) }\end{array}$} \\
\hline Range & Score & Range & Score & & Score \\
\hline $0-3$ & 2 & $0 \%-20 \%$ & 2 & Ya & 5 \\
$4-6$ & 4 & $21 \%-40 \%$ & 4 & Tidak & 0 \\
$6-8$ & 6 & $41 \%-60 \%$ & 6 & & \\
$9-11$ & 8 & $61 \%-80 \%$ & 8 & & \\
$>11$ & 10 & $>80 \%$ & 10 & & \\
\hline
\end{tabular}

Sumber:Wahidahwati, 2012

Tabel 2, menunjukkan skor minimal yang diberikan adalah 2 dan skor maksimal adalah 10. Jika komite audit memiliki keahlian dibidang akuntansi diberikan skor 5 dan skor 0 jika tidak memiliki keahlian dibidang akuntansi. Komite audit dihitung dengan menjumlahkan skor dari ukuran komite audit, proporsi komite audit independen dan keahlian kemudian mengalikan jumlah skor tersebut dengan $20 \%$.

Kriteria pemberian skor dari instrumen GCG yaitu manajemen disajikan pada Tabel 3, sebagai berikut. 
Tabel 3. Manajemen

\begin{tabular}{cccccc}
\hline \multicolumn{5}{c}{ Manajemen : $20 \%$} \\
\hline \multicolumn{2}{c}{ Ukuran Dewan Direksi } & \multicolumn{2}{c}{ Kepemilikan Manajerial } & \multicolumn{2}{c}{ Hubungan Keluarga } \\
\hline Range & Score & Range & Score & & Score \\
\hline $0-3$ & 2 & $0 \%-20 \%$ & 2 & Ya & 0 \\
$4-6$ & 4 & $21 \%-40 \%$ & 4 & Tidak & 5 \\
$6-8$ & 6 & $41 \%-60 \%$ & 6 & & \\
$9-11$ & 8 & $61 \%-80 \%$ & 8 & & \\
$>11$ & 10 & $>80 \%$ & 10 & & \\
\hline
\end{tabular}

Sumber:Wahidahwati, 2012

Tabel 3, menunjukkan skor minimal yang diberikan adalah 2 dan skor maksimal adalah 10. Jika dalam manajemen terdapat hubungan keluarga maka diberikan skor 0 dan skor 5 jika tidak terdapat hubungan keluarga. Manajemen dihitung dengan menjumlahkan skor dari ukuran dewan direksi, kepemilikan manajerial dan hubungan keluarga kemudian mengalikan jumlah skor tersebut dengan $20 \%$.

Sampel dalam penelitian ini dipilih menggunakan metode purposive sampling. Metode pengumpulan data yang digunakan dalam penelitian ini adalah studi kepustakaan dan dokumentasi sedangkan teknik analisis yang digunakan dalam penelitian ini adalah analisis linear berganda. Adapun persamaan analisis regresi linear berganda yang digunakan untuk pengujian ini adalah sebagai berikut.

$\mathrm{CED}=\alpha+\beta 1 \mathrm{UP}+\beta 2 \mathrm{PROF}+\beta 3 \mathrm{LEV}+\beta 4 \mathrm{TI}+\beta 5 \mathrm{GCG}+\varepsilon$

Keterangan:

$\mathrm{CED}=$ Pengungkapan emisi karbon

a $\quad=$ Konstanta

$\beta 1=$ Koefisien regresi ukuran perusahaan (UP)

$\beta 2=$ Koefisien regresi profitabilitas $(\mathrm{PROF})$

$\beta 3=$ Koefisien regresi leverage $(\mathrm{LEV})$

$\beta 4=$ Koefisien regresi tipe industri $(\mathrm{TI})$

$\beta 5=$ Koefisien regresi good corporate governance (GCG)

$\varepsilon \quad=$ Eror

\section{HASIL DAN PEMBAHASAN}

Penelitian ini menggunakan seluruh emiten Bursa Efek Indonesia yang mengungkapkan informasi terkait emisi karbon pada tahun 2018 sebagai sampel. Jumlah sampel adalah 38 perusahaan. Terdapat satu amatan yang memiliki nilai z-score 5,72 sehingga dianggap sebagai outlier dan dikeluarkan dari sampel. Dengan demikian maka sampel akhir yang digunakan dalam analisis data lebih lanjut terdiri atas 37 perusahaan. Tabel 4, menyajikan statistik deskriptif variabel penelitian. Tabel tersebut menunjukkan bahwa secara umum variabel penelitian memiliki sebaran data yang baik, kecuali profitabilitas (PROF) yang memiliki deviasi standar yang lebih besar dari nilai rata-ratanya.

Analisis statistik deskriptif digunakan untuk mendeskripsikan suatu data yang dilihat dari nilai maksimum, nilai minimum, nilai rata-rata dan nilai deviasi standar. Hasil dari statistik deskriptif disajikan pada Tabel 4. 
Tabel 4. Statistik Deskripstif

\begin{tabular}{lccccc}
\hline \multicolumn{1}{c}{ Variabel } & $\mathrm{N}$ & Minimum & Maksimum & Rata-rata & $\begin{array}{c}\text { Deviasi } \\
\text { Standar }\end{array}$ \\
\hline UP & 37 & 14,58 & 19,66 & 17,07 & 1,15 \\
PROF & 37 & $-0,06$ & 0,47 & 0,07 & 0,11 \\
LEV & 37 & 0,16 & 2,79 & 1,12 & 0,64 \\
TI & 37 & 0,00 & 1,00 & 0,84 & 0,37 \\
GCG & 37 & 10,40 & 16,05 & 13,50 & 1,27 \\
CED & 37 & 0,11 & 0,61 & 0,25 & 0,15 \\
\hline
\end{tabular}

Sumber: Data Penelitian, 2019

Dalam penelitian ini dilakukan uji asumsi klasik yang bertujuan untuk memastikan bahwa model yang dibuat sudah memenuhi asumsi-asumsi dasar dalam analisis regresi. Adapun uji asumsi klasik yang digunakan dalam penelitian ini adalah uji normalitas, uji multikolinearitas, dan uji heteroskedastisitas. Uji autokorelasi tidak diperlukan karena data bersifat crosssectional.

Uji normalitas yang digunakan adalah Uji Kolmogorov-Smirnov. Tabel 5, menunjukkan nilai Kolmogorov-Smirnov $Z$ sebesar 0,91 dengan tingkat signifikansi 0,38 yang berada di atas tingkat signifikansi yang telah ditentukan yaitu 0,05 . Berdasarkan hal tersebut berarti residual regresi berdistribusi normal (asumsi normalitas terpenuhi).

Tabel 5. Hasil Uji Normalitas

\begin{tabular}{llr}
\hline & & Unstandardized Residual \\
\hline$N$ & & 37 \\
Normal Parametersa,b & Mean & 0,00 \\
& Std. Deviation & 0,12 \\
Most Extreme Differences & Absolute & 0,15 \\
& Positive & 0,15 \\
& Negative & $-0,09$ \\
Kolmogorov-Smirnov Z & & 0,91 \\
Asymp.Sig.(2-tailed) & & 0,38 \\
\hline
\end{tabular}

Sumber: Data Penelitian, 2019

Uji multikolinearitas bertujuan untuk mengetahui hubungan antar variabel bebas yang dilihat pada nilai tolerance dan VIF (variance inflation factor). Jika nilai tolerance lebih dari 0,1 dan VIF kurang dari 10 maka berarti tidak terdapat korelasi diantara masing-masing variabel bebas. Tabel 6, menunjukkan bahwa semua variabel independen yang digunakan dalam penelitian memiliki nilai tolerance yang lebih dari 0,1 dan nilai VIF yang kurang dari 10 hal ini berarti bahwa antar variabel bebas dalam model regresi tidak ada multikolinearitas.

Tabel 6. Hasil Uji Multikolinearitas

\begin{tabular}{|c|c|c|}
\hline Variabel & Tolerance & VIF \\
\hline UP & 0,89 & 1,13 \\
\hline PROF & 0,83 & 1,20 \\
\hline LEV & 0,88 & 1,14 \\
\hline TI & 0,94 & 1,06 \\
\hline GCG & 0,84 & 1,19 \\
\hline
\end{tabular}

Sumber: Data Penelitian, 2019 
Uji heteroskedastisitas berfungsi untuk menguji apakah dalam model regresi terdapat varian yang tidak sama dalam kesalahan pengganggu. Penelitian ini menggunakan Uji Glejser untuk mendeteksi adanya heteroskedastisitas. Jika hasil regresi residual absolut pada variabel bebas lebih dari 0,05 maka model regresi dapat dinyatakan tidak mengandung heteroskedastisitas (Ghozali, 2013). Tabel 7, menunjukan bahwa tidak ada satupun variabel bebas yang nilai signifikansi sama atau kurang dari 0,05. Berdasarkan hasil tersebut maka dapat diambil kesimpulan bahwa model regresi yang digunakan tidak mengandung masalah heteroskedastisitas.

Tabel 7. Hasil Uji Heteroskedastisitas

\begin{tabular}{lcc}
\hline & Variabel & Sig \\
\hline UP & 0,40 \\
PROF & 0,48 \\
LEV & 0,13 \\
TI & 0,13 \\
GCG & 0,62 \\
\hline
\end{tabular}

Sumber: Data Penelitian, 2019

Hasil regresi linear berganda disajikan pada Tabel 8, Ukuran perusahaan dan profitabilitas ternyata tidak memengaruhi pengungkapan emisi karbon. Sesuai hipotesis, leverage memiliki pengaruh negatif pada pengungkapan emisi karbon. Tipe industri dan good corporate governance berpengaruh positif pada pengungkapan emisi karbon. Berdasarkan hasil regresi maka dirumuskan persamaan sebagai berikut.

$\mathrm{CED}=-0,53-0,10 \mathrm{LEV}+0,14 \mathrm{TI}+0,04 \mathrm{GCG}$

Tabel 8. Hasil Analisis Regresi Linear Berganda

\begin{tabular}{|c|c|c|c|c|c|}
\hline \multirow[t]{2}{*}{ Model } & \multicolumn{2}{|c|}{$\begin{array}{l}\text { Unstandardized } \\
\text { Coefficients }\end{array}$} & \multirow{2}{*}{$\begin{array}{c}\begin{array}{c}\text { Standardized } \\
\text { Coefficients }\end{array} \\
\text { Beta }\end{array}$} & \multirow[t]{2}{*}{$\mathrm{t}$} & \multirow[t]{2}{*}{ Sig. } \\
\hline & B & Std. Error & & & \\
\hline Konstanta & $-0,53$ & 0,37 & & $-1,44$ & 0,16 \\
\hline UP & 0,02 & 0,02 & 0,13 & 0,85 & 0,40 \\
\hline PROF & $-0,60$ & 0,34 & $-0,27$ & $-1,78$ & 0,09 \\
\hline LEV & $-0,10$ & 0,04 & $-0,43$ & $-2,89$ & 0,00 \\
\hline TI & 0,14 & 0,06 & 0,34 & 2,40 & 0,02 \\
\hline GCG & 0,04 & 0,02 & 0,33 & 2,21 & 0,04 \\
\hline Adjusted $\mathrm{R}^{2}$ & & & & & 0,31 \\
\hline F-hitung & & & & & 4,20 \\
\hline SignifikansiF & & & & & 0,00 \\
\hline
\end{tabular}

Sumber: Data Penelitian, 2019

Koefisien determinasi (adjusted $\mathrm{R}^{2}$ ) menunjukan nilai sebesar 0,31 yang berarti bahwa 31 persen dari variansi pengungkapan emisi karbon perusahaan dijelaskan oleh variabel leverage, tipe industri dan GCG, sedangkan sisanya sebesar 69 persen dipengaruhi oleh faktor-faktor lain yang tidak dimasukkan dalam model regresi. Tabel 8, menunjukkan nilai $F_{\text {hitung }}$ sebesar 4,20 dengan signifikansi 0,00. Hasil tersebut menunjukan bahwa model persamaan dalam penelitian ini layak untuk digunakan. Nilai konstanta negatif $(-0,53)$ memperlihatkan bahwa pengungkapan emisi karbon bernilai negatif ketika variabel bebas bernilai nol. 
Uji hipotesis dilakukan untuk memperlihatkan pengaruh variabel independen pada variabel dependen. Hipotesis dinyatakan diterima atau ditolak berdasarkan tingkat signifikansi 0,05 (5\%). Pengujian pengaruh variabel ukuran perusahaan pada pengungkapan emisi karbon memperlihatkan hasil tidak signifikan dengan nilai signifikansi 0,40, yang artinya lebih besar dari 0,05, sehingga hipotesis pertama dalam penelitian ini yang menyatakan ukuran perusahaan memiliki pengaruh positif pada pengungkapan emisi karbon ditolak. Temuan tersebut sejalan dengan penelitian Irwhantoko \& Basuki (2016), Linggasari (2015), Pratiwi (2018) yang menyatakan bahwa ukuran perusahaan tidak berpengaruh pada pengungkapan emisi karbon.

Perusahaan yang memiliki aset yang banyak belum tentu akan dapat memberikan pengungkapan emisi karbon yang luas, karena perusahaan besar di Indonesia belum memahami pentingnya mengurangi pencemaran dari emisi karbon yang berdampak sangat besar bagi lingkungan. Dampak yang ditimbulkan perusahaan besar terhadap lingkungan lebih besar daripada perusahaan kecil, maka dari itu memerlukan peraturan yang ketat dari pemerintah terkait kewajiban perusahaan besar dalam mengungkapkan secara lebih luas terkait emisi karbon yang disebabkan dari aktivitas produksi perusahaan.

Besar kecilnya ukuran perusahaan tidak berpengaruh pada pengungkapan emisi karbon kemungkinan juga perusahaan yang besar lebih banyak melakukan kegiatan yang berkaitan dengan masyarakat untuk bisa mendapatkan legitimasi, dibandingkan melakukan kegiatan yang berkaitan dengan lingkungan seperti mengurangi dampak perubahan iklim. Hasil penelitian ini tidak mendukung penelitian Jannah \& Muid (2014), Eleftheriadis \& Anagnostopoulou (2015), Stanny \& Ely (2008) dan Lorenzo et al. (2009) yang menunjukkan bahwa ukuran perusahaan mempunyai hubungan yang positif pada pengungkapan emisi karbon. Hasil yang berbeda kemungkinan disebabkan oleh adanya perbedaan perusahaan yang menjadi sampel penelitian.

Pengujian hipotesis kedua mengenai pengaruh profitabilitas pada pengungkapan emisi karbon memperlihatkan hasil tidak signifikan dengan nilai signifikansi sebesar 0,09, lebih besar dari 0,05. Maka disimpulkan bahwa hipotesis kedua ditolak. Tingkat profitabilitas tidak berpengaruh pada pengungkapan emisi karbon. Hal tersebut kemungkinan disebabkan karena biaya yang dikeluarkan untuk mereduksi emisi karbon dengan menggunakan peralatan yang dapat mengurangi emisi tidak sebanding dengan keuntungan yang didapat oleh perusahaan. Dewi et al. (2019) menyatakan bahwa peningkatan biaya lingkungan dianggap tidak memberikan manfaat atau keuntungan lingkungan yang lebih besar bagi perusahaan. Hasil penelitian ini sejalan dengan penelitian Pratiwi (2018), Irwhantoko \& Basuki (2016) dan Pratiwi \& Sari (2016) yang menyatakan bahwa profitabilitas tidak berpengaruh pada pengungkapan emisi karbon.

Hipotesis ketiga menyatakan bahwa leverage berpengaruh negatif pada pengungkapan emisi karbon. Pengujian pengaruh leverage pada pengungkapan emisi karbon memperlihatkan pengaruh yang signifikan dengan nilai signifikansi sebesar 0,00 dan nilai koefisien regresi sebesar -0,10. Hal ini berarti leverage berpengaruh negatif pada pengungkapan emisi karbon, sehingga 
hipotesis ketiga dalam penelitian ini diterima. Semakin tinggi leverage maka semakin rendah pengungkapan emisi karbon. Perusahaan dengan tingkat leverage yang tinggi akan lebih mempertimbangkan tanggung jawabnya untuk membayar kewajibannya kepada para debtholder dibandingkan untuk melakukan pengungkapan terkait emisi karbon. Tingkat leverage yang tinggi juga memberikan tekanan kepada perusahaan untuk memberikan perhatian lebih besar kepada faktor-faktor yang bernilai ekonomis dibandingkan faktor sosial maupun lingkungan. Hasil penelitian ini sejalan dengan penelitian Irwhantoko \& Basuki (2016) dan Clarkson et al. (2008) yang menemukan bahwa leverage berpengaruh negatif pada pengungkapan emisi karbon.

Hipotesis keempat menyatakan bahwa tipe industri berpengaruh positif pada pengungkapan emisi karbon. Pengujian pengaruh tipe industri pada pengungkapan emisi karbon memperlihatkan pengaruh yang signifikan dengan nilai signifikansi sebesar 0,02 dan nilai koefisien 0,14. Hal ini berarti bahwa perusahaan yang tergolong high profile melakukan pengungkapan yang lebih tinggi dibandingkan ind ustri yang tergolong low profile. Dengan demikian maka hipotesis keempat dinyatakan diterima. Hasil penelitian ini mendukung penelitian yang dilakukan Choi et al. (2013) yang menunjukkan perusahaan pada industri high profile lebih banyak melakukan pengungkapan emisi karbon. Hasil penelitian ini juga sejalan dengan penelitian Jannah \& Muid (2014) yang menyatakan tipe industri berpengaruh positif pada pengungkatpan emisi karbon.

Hipotesis kelima menyatakan bahwa good corporate governance berpengaruh positif pada pengungkapan emisi karbon. Pengujian pengaruh good corporate governance pada pengungkapan emisi karbon memperlihatkan pengaruh yang signifikan dengan nilai signifikansi sebesar 0,04 dan koefisien 0,04 . Hal ini berarti good corporate governance memiliki pengaruh positif pada pengungkapan emisi karbon, sehingga hipotesis kelima dinyatakan diterima. Sejalan dengan penelitian yang dilakukan Choi et al. (2013) menemukan bahwa kualitas corporate governance berpengaruh positif pada pengungkapan emisi karbon, sejalan dengan penelitian Habbash (2016) yang menyatakan bahwa GCG menjadi sarana yang mengakomodasi hal yang dulunya tidak dianggap perlu yaitu hubungan bisnis dengan lingkungan.

Penelitian ini mendukung teori legitimasi dan teori stakeholder. Hasil penelitian menunjukkan semakin tinggi tingkat leverage suatu perusahaan maka pengungkapan informasi perusahaan terkait emisi karbon semakin rendah. Hal ini mendukung teori stakeholder bahwa perusahaan selalu menjaga hubungan dengan para stakeholder. Tingkat leverage tinggi menyebabkan perusahaan mengutamakan melunasi liabilitasnya daripada menyediakan informasi tambahan pada laporan tahunan.

Hasil penelitian menyatakan perusahaan pada industri yang tergolong industri high profile melakukan pengungkapan yang lebih tinggi mengenai emisi karbon. Hal ini sejalan dengan teori legitimasi yang digunakan dalam penelitian ini. Perusahaan yang memiliki dampak yang tinggi terhadap lingkungan memperoleh tekanan yang lebih dari masyarakat dalam pertanggungjawabannya terhadap lingkungan. Perusahaan melakukan pengungkapan emisi karbon untuk mendapatkan legitimasi dari masyarakat. 
Perusahaan yang memiliki kualitas corporate governance yang baik memberikan pengungkapan emisi karbon yang lebih tinggi. Hasil tersebut mendukung teori legitimasi, bahwa corporate governance suatu perusahaan berkembang didasarkan pada teori legitimasi. Perusahaan dalam menjalankan usahanya dituntut agar peduli terhadap lingkungan dengan mengembangkan kebijakan untuk mengurangi emisi akibat aktivitas perusahaan. Hal ini sejalan dengan prinsip utama good corporate governance yaitu prinsip responsibility. Pengaruh kualitas corporate governance pada pengungkapan emisi karbon juga mendukung teori stakeholder. Teori stakeholder menyatakan perusahaan tidak hanya harus berfokus pada kepentingannya sendiri, namun harus mampu memberikan manfaat bagi stakeholders. Perusahaan yang memiliki tata kelola yang baik memberikan secara transparan informasi terkait emisi karbon perusahaan yang bermanfaat bagi para stakeholder.

\section{SIMPULAN}

Berdasarkan hasil analisis data, dapat disimpulkan mengenai faktor-faktor yang memengaruhi pengungkapan emisi karbon pada perusahaan yang terdaftar di Bursa Efek Indonesia. Hasil pengujian menunjukkan leverage berpengaruh negatif pada pengungkapan emisi karbon. Hal ini berarti semakin tinggi tingkat leverage suatu perusahaan maka pengungkapan emisi karbon perusahaan semakin rendah. Tipe industri berpengaruh positif pada pengungkapan emisi karbon. Hal ini berarti bahwa tipe industri yang tergolong industri high profile melakukan pengungkapan yang lebih tinggi mengenai emisi karbon. Good corporate governance berpengaruh positif pada pengungkapan emisi karbon. Hal ini berarti semakin baik kualitas corporate governance suatu perusahaan maka pengungkapan emisi karbon perusahaan semakin tinggi. Ukuran perusahaan tidak berpengaruh pada pengungkapan emisi karbon. Hal ini berarti bahwa besar kecilnya perusahaan tidak memengaruhi pengungkapan emisi karbon perusahaan. Profitabilitas tidak berpengaruh pada pengungkapan emisi karbon. Hal ini berarti bahwa tinggi rendahnya profitabilitas perusahaan tidak memengaruhi pengungkapan emisi karbon perusahaan.

Hasil penelitian menunjukkan tingkat leverage berpengaruh negatif pada pengungkapan emisi karbon. Penyedia pinjaman (kreditur) agar lebih mendukung kegiatan perusahaan terkait dengan lingkungan seperti upaya penurunan emisi karbon. Hal tersebut dapat mengurangi tekanan perusahaan dari kreditur sehingga dapat membantu perusahaan dengan tingkat leverage dalam mengungkapkan emisi karbon secara lebih luas. Hasil penelitian menunjukkan pengaruh positif tipe industri pada pengungkapan emisi karbon. Sehubungan dengan itu maka disarankan agar perusahaan yang tergolong industri low profile juga perlu mengungkapkan mengenai emisi karbon lebih luas sehingga bisa memberi informasi yang lengkap untuk para stakeholder. Hasil penelitian menunjukkan pengaruh positif good corporate governance pada pengungkapan emisi karbon. Perusahaan perlu mengungkapkan informasi terkait emisi karbon secara lebih luas sehingga memehuni prinsip dari good corporate governance yaitu prinsip responsibilitas dan transparansi. Dengan adanya pengungkapan emisi karbon dapat menjadi salah satu fasilitas bagi perusahaan untuk menciptakan kualitas corporate governance yang lebih baik. 
Koefisien determinasi (adjusted $\mathrm{R}^{2}$ ) penelitian ini adalah 31 persen, yang berarti 69 pengungkapan emisi karbon dijelaskan oleh variabel lain yang tidak digunakan dalam model penelitian ini. Melihat adjusted $\mathrm{R}^{2}$ yang relatif kecil tersebut maka peneliti selanjutnya dapat menambah periode penelitian ataupun menambah variabel bebas lain atau variabel kontrol seperti kinerja lingkungan, media exposure, regulator dan lain-lain. Bagi peneliti selanjutnya disarankan agar meneliti lebih mendalam terkait pengaruh variabel ukuran perusahaan dan variabel profitabilitas pada pengungkapan emisi karbon. Peneliti selanjutnya dapat menggunakan proksi lain sebagai pengukuran variabel. Misalnya, peneliti dapat mengganti pengukuran variabel ukuran perusahaan dari $\ln$ (total aset) menjadi $\ln$ (total ekuitas) dan peneliti dapat mengganti pengukuran variabel profitabilitas dengan menggunakan rasio lain seperti rasio net profit margin, return on equity (ROE) dan lain-lain. Peneliti selanjutnya juga dapat mempertimbangkan untuk mengkaji kemungkinan bahwa ukuran perusahaan dan profitabilitas berfungsi sebagai variabel pemoderasi atas pengungkapan emisi karbon.

\section{REFERENSI}

Andrew, \& Cortese, C. L. (2011). Carbon Disclosure: Comparability the Carbon Disclosure Project and the Greenhouse Gas Protocol. Australian Accounting Business and Finance Journal, 5(4), 5-8.

Astuti, N., \& Wirama, D. (2016). Pengaruh Ukuran Perusahaan, Tipe Industri, Dan Intensitas Research and Development Pada Pengungkapan Modal Intelektual. E-Jurnal Akuntansi, 15(1), 522-548.

Choi, B. B., Lee, D., \& Psaros, J. (2013). An analysis of Australian Company Carbon Emission Disclosures. Pacific Accounting Review, 25(1), 58-79.

Clarkson, P. M., Li, Y., Richardson, G. D., \& Vasvari, lorin P. (2008). Revisiting the relation between environmental performance and environmental disclosure: An empirical analysis. Accounting, Organizations and Society, 33(4-5), 303-327.

Cotter, J., \& Najah, M. M. (2012). Institutional Investor Influence On Global Climate Change Disclosure Practice. Australian Journal of Management, 37(2), 169-187. https://doi.org/https://doi.org/10.1177/0312896211423945

D’Amico, E., Coluccia, D., Fontana, S., \& Solimene, S. (2016). Factors Influencing Corporate Environmental Disclosure. Business Strategy and the Environment, 25(3), 178-192. https://doi.org/https://doi.org/10.1002/bse.1865

Deegan, C., \& Unerman, J. (2011). Financial accounting theory. London: UK Higher Education Business Accounting.

Dewi, I. A. P. O. Y, \& Yasa, G. W. (2017). Pengaruh Ukuran Profitabilitas, Tipe Industri Dan Kinerja Lingkungan Terhadap Environmental Disclosure. EJurnal Akuntansi Universitas Udayana, 20(3), 2362-2391.

Dewi, K. L. G., Yenni, L. M., \& Nyoman, R. N. (2019). Determinasi Carbon Emission Disclosure Perusahaan Manufaktur. E-Jurnal Akuntansi, 28(1), 613640. https://doi.org/https://doi.org/10.24843/EJA.2019.v38.i01.p24

Dowling, J., \& Pfeffer, J. (1975). Organisational Legitimacy: Social Values and Organisational Behavior. Sociological Perspectives, 18(1), 122-136. https://doi.org/https://doiorg/10.2307/1388226 
Eleftheriadis, I. M., \& Anagnostopoulou, E. G. (2015). Relationship between Corporate Climate Change Disclosures and Firm Factors. Business Strategy and the Environment, 24(8), 780-789. https://doi.org/10.1002/bse.1845

Ghomi, Z. B. \& Leung P. (2013). An Empirical Analysis of the Determinants of Greenhouse Gas Voluntary Disclosure in Australia. Accounting and Finance Research, 2(1), 110-127. https://doi.org/10.5430/afr.v2n1p110

Ghozali, I. (2013). Aplikasi Analisis Multivariate dengan Program SPSS (2nd ed.). Semarang: Badan Penerbit Universitas Diponegoro.

Habbash, M. (2016). Corporate Governance and Corporate Social Responsibility Disclosure: Evidence from Saudi Arabia. Social Responsibility Joumal, 12(4), 740-754.

Irwhantoko, I., \& Basuki, B. (2016). Carbon Emission Disclosure: Studi pada Perusahaan Manufaktur Indonesia. Jurnal Akuntansi Dan Keuangan, 18(2), 92-104. https://doi.org/10.9744/jak.18.2.92-104

Jannah, R., \& Muid, D. (2014). Analisis Faktor-Faktor Yang Mempengaruhi Carbon Emission Disclosure Pada Perusahaan di Indonesia (Studi Empiris pada Perusahaan yang Terdaftar di Bursa Efek Indonesia Periode 20102012). Journal of Accounting, 3(2).

Linggasari, E. (2015). Pengaruh Karakteristik Perusahaan Terhadap Carbon Emission Disclosure. Fakultas Ekonomi Universitas Negeri Malang Jurnal Ekonomi Bisnis, 1, 63-69.

Lorenzo, J. M. P., Domínguez, L. R., Álvarez, I. G., \& Sánchez, I. M. G. (2009). Factors Influencing the Disclosure of Greenhouse Gas Emissions in Companies World-Wide. Journal of Management Decisions, 47(7), 1133-1157.

Luo, L., Tang, Q., \& Lan, Y. (2013). Comparison of Propensity for Carbon Disclosure between Developing and Developed Countries. Accounting Research Journal, 26(1), 6-34.

Peng, J., Sun, J., \& Luo, R. (2015). Corporate Voluntary Carbon Information Disclosure: Evidence from China's Listed Companies. World Economy, 38(1), 91-109. Retrieved from https://doi.org/10.1111/twec.12187

Pradini, H. S. (2013). The Analysis of Information Content towards Greenhouse Gas Emissions Disclosure in Indonesia Companies. Diponegoro Journal of Accounting, V 2, No 2, Halaman 1-12.

Pratiwi, P., C., \& Sari, V., F. (2016). Pengaruh Tipe Industri Media Explosure dan Profitabilitas Terhadap Carbon Emission Disclosure. Jurnal WRA, 4(2), 829844.

Pratiwi, D. N. (2018). Implementasi Carbon Emission Disclosure di Indonesia. Jurnal Ilmiah Akuntansi Dan Bisnis, (2007), 101. https://doi.org/10.24843/JIAB.2018.v13.i02.p04

Presiden Republik Indonesia. Perpres No. 61 Tahun 2011 mengenai Rencana Aksi Nasional Penurunan Emisi Gas Rumah Kaca. (2011). Indonesia.

Putri, P. C. T., \& Wirajaya, I. G. A. (2019). Implementasi Corporate Social Responsibility Dan Dampaknya Terhadap Kinerja Keuangan. E-Jurnal Akuntansi Universitas Udayana, 28, 407-433.

Stanny, E., \& Ely, K. (2008). Corporate Environmental Disclosures About The Effects of Climate Change. Corporate Social Responsibility and Environmental Management, 15(6), 338-348. 
Undang-Undang Republik Indonesia Nomor 17 Tahun 2004 Tentang Pengesahan Kyoto Protocol to The United Nations Framework Convention on Climate Change (Protokol Kyoto Atas Konvensi Kerangka Kerja Perserikatan Bangsa-Bangsa Tentang Perubahan Iklim). (2004). Indonesia

Urmila, D. N. M., \& Mertha, I. M. (2017). Tipe Perusahaan Sebagai Pemoderasi Pengaruh Ukuran Perusahaan, Profitabilitas, Dan Kepemilikan Asing pada Pengungkapan Corporate Social Responsibility di Perusahaan Manufaktur yang Terdaftar di Bursa Efek Indonesia. E-Jurnal Akuntansi, 19(3), 2145-2174.

Wahidahwati. (2012). The Influence of Financial Policies on Earning Management, Moderated By Good Corporate Governance. Jurnal Ekonomi Dan Keuangan, 16(4), 507-522.

Wang, J., Lin, S., \& Yao, S. (2013). The Determinants of Corporate Social Responsibility Disclosure: Evidence from China. The Journal of Applied Business Research, 29(6).

Wulandari, K. T., \& Wirajaya, I. G. A. (2014). Pengaruh Pengungkapan Corporate Social Responsibility Terhadap Earningss Response Coefficient Pada Perusahaan High Profile. E-Jurnal Akuntansi Universitas Udayana, 11(1), 1-18. 